\title{
Therapeutic communities enter the world of evidence-based practice
}

\author{
Rex Haigh
}

\begin{abstract}
Summary
This editorial provides the modern-day context for a long-established psychiatric treatment, democratic therapeutic communities. As this treatment is now such a small field in psychiatry, readers may not have enough background to be able to place the research in a suitable context. This includes the previous gap in experimental research, the difference between the modern model and the one used in the 20th century and the general field of personality disorder evidence.
\end{abstract}

\section{Declaration of interest}

R.H. leads the Enabling Environments project at the Royal College of Psychiatrists' Centre for Quality Improvement (CCQI).

\section{Copyright and usage}

(c) The Royal College of Psychiatrists 2017.
Rex Haigh is a consultant medical psychotherapist at the Berkshire Healthcare NHS Foundation Trust and honorary professor of therapeutic environments and relational health at the School of Sociology and Social Policy, Nottingham University.

Recently in the BJPsych, Steve Pearce and colleagues ${ }^{1}$ demonstrated that it is possible to do an experimental study on a complex treatment modality that has been in use for over 50 years. Theirs is an important study, and is a landmark in being the first ever randomised controlled trial on democratic therapeutic communities for personality disorder. In the seven decades since their role in psychiatric services was established, clinicians in therapeutic communities have generally preferred qualitative approaches to research. ${ }^{2}$ These were seen to have a more congruent epistemological basis, but were a richer vein for anthropological and sociological enquiry than they were for clinical studies. An extensive systematic review in 1999 found that few studies were suitable for inclusion in the meta-analysis, and those that were included were too heterogeneous and imprecise to give robust results. ${ }^{3}$

\section{Modern-day therapeutic communities}

For psychiatrists who remember democratic therapeutic communities in their heyday, they were based on Rapoport's four themes (democratisation, permissiveness, reality confrontation and communalism) which he identified at Henderson Hospital in the late 1950s. ${ }^{4}$ Although the service in Pearce et al's study is based on some of these fundamental principles, they are overlaid with several decades of development and modification. Newer therapeutic communities now bear few superficial resemblances to these residential services, which were formed in the heat of the social psychiatry revolution of the 1950s and 1960s. No wholly group-based residential therapeutic communities now remain in the National Health Service (NHS), and all of those that still function are day units, as in this study. ${ }^{5,6}$ The laissez-faire attitude of 'leave it to the group' rarely prevails, there is a high level of structure and order, and there is very little opaque psychoanalytic interpretation delivered by remote therapists. Modern therapeutic communities have a strong emphasis on empowerment, openness and 'ordinariness', which soon dispel any notions of therapeutic mysteriousness and charismatic leadership. They are tightly managed services with clear admission, review, progression and discharge protocols. ${ }^{7}$

In 2002, one of the first quality networks of the Royal College of Psychiatrists' Centre for Quality Improvement (CCQI) was the 'Community of Communities'. It helped democratic therapeutic communities to agree the nature of best practice and to consistently deliver it. ${ }^{8}$ Part of this process involved the distillation of ten core values that underlie the measurable standards. These would be entirely familiar to early therapeutic community pioneers: a culture of belongingness, enquiry and empowerment; democratic processes whereby no decisions can be made without due discussion and understanding; and the fundamental importance of establishing and maintaining healthy relationships (which are not always comfortable and are seldom without conflict). This work has also led to the 'Enabling Environments' award at the Royal College, and the development of 'psychologically informed planned environments' (PIPEs) in criminal justice settings, and 'psychologically informed environments' (PIEs) in the homelessness sector. ${ }^{9}$

\section{Their role in treatment for personality disorder}

The publication of outcome studies for personality disorder treatment have had something of the quality of a 'horse race' or 'beauty contest' in the past decade. New treatments have been constituted from various old psychological theories, which have been branded and packaged, then manualised and researched with much energy and competitiveness. In this way, they have been suitable for 'selling' to mental health commissioners as simple value-free 'commodities' or 'products. ${ }^{10}$ In a way, Pearce et al's study indicates that therapeutic communities have now entered this race. However, it is worth proposing that their study is not of a simple 'brand' of treatment, but of a therapeutic philosophy with a long and distinguished heritage, which has now been adapted to fit into the wider 'whole system' of a 21 st-century mental health service. Therapeutic communities offer a democratic way of conducting therapeutic business, demand specific attention to the coherent and coordinated use of the different therapeutic approaches, and deliberately provide an overall therapeutic environment. ${ }^{11}$ These do not often happen in other therapies. 
Therapeutic communities also specialise in being able to treat those who have a particularly severe presentation of personality disorder, such as in prisons. This severity can be measured by diagnostic criteria, comorbidity, risk, complexity or unmanageability. ${ }^{12}$ The therapeutic environment, including techniques such as peer mentoring and deliberate informality, facilitates engagement of people who would otherwise be 'untreatable'. Also, by managing risk primarily through continuing, empathic and intense therapeutic relationships, therapeutic communities can manage levels of risk that would be unacceptable in other services. This study demonstrates that democratic therapeutic communities have now started to accumulate the evidence to earn a place in the therapeutic pantheon for moderate and severe personality disorder.

Rex Haigh, MA, BM, BCh, MRCGP, FRCPsych, MembInstGA, Berkshire Healthcare NHS Foundation Trust, ASSisT Office, Upton Hospital, Slough SL1 2BJ, UK. Email: rexhaigh@nhs.net

First received 25 Sep 2016, final revision 21 Dec 2016, accepted 19 Jan 2017

\section{References}

1 Pearce S, Scott L, Attwood G, Saunders K, Dean M, De Ridder R, et al Democratic therapeutic community treatment for personality disorder: randomised controlled trial. Br J Psychiatry 2017; 210: 149-56.
2 Lees J, Manning N, Menzies D, Morant N. A Culture of Enquiry: Research Evidence and the Therapeutic Community. JKP, 2004.

3 Lees J, Manning N, Rawlings B. Therapeutic Community Effectiveness: A Systematic International Review of Therapeutic Community Treatment for People with Personality Disorders and Mentally Disordered Offenders. University of York Centre for Reviews and Dissemination, 1999.

4 Rapoport R. Community as Doctor. Tavistock, 1960.

5 Haigh R. The new day TCs: five radical features. Ther Communities 2007; 28 : 111-26.

6 Pearce S, Haigh R. Mini therapeutic communities: a new development in the United Kingdom. Ther Communities 2008; 29: 111-24.

7 Pearce S, Haigh R. A Handbook of Democratic Therapeutic Community Theory and Practice. JKP, 2017.

8 Haigh R, Tucker S. Democratic development of standards: the Community of Communities - a quality network of therapeutic communities. Psychiatr $Q$ 2004; 75: 263-77.

9 Haigh R, Harrison T, Johnson R, Paget S, Williams S. Psychologically informed environments and the "Enabling Environments" initiative. Hous Care Support 2012; 15: 34-42.

10 Haigh R. Industrialisation of therapy and the threat to our ethical integrity. Personal Ment Health 2014; 8: 251-3.

11 Haigh R. The quintessence of a therapeutic environment. Ther Communities 2013; 34: 6-15.

12 Department of Health. Recognising Complexity: Commissioning Guidance for Personality Disorder Services. Department of Health, 2009.

\section{psychiatry in music}

\section{'The eyes have it'. Syd Barrett and Pink Floyd}

\section{Abdi Sanati and Stephanie Young}

The British progressive rock band Pink Floyd has been one of the most successful acts in the history of rock/pop. During the past 50 years they have sold tens of millions of albums and sold out several massive gigs. They are going to have their own special exhibition in the Victoria and Albert Museum in London, a testimony to their success. The history of the band, however, has been far from happy.

The breakdown of their first lead guitar player and songwriter, Syd Barrett, to mental illness had a profound effect on the band. Mental illness is reflected in the lyrics of several of their songs. In 'If' from the album Atom Heart Mother they sing: 'If I go insane, please don't put your wires in my brain'. The song 'Brain Damage', from the multi-platinum album Dark Side of The Moon, is explicitly about mental illness. There are several references in the album The Wall, for example to derealisation in 'Comfortably Numb'. But the impact of Barrett on the band is never more profound and explicit than on their album Wish You Were Here, arguably their best. The song 'Shine on You Crazy Diamond' is a tribute to their former band leader. It is one of their most personal and poignant songs, musically and lyrically. The description of Syd Barrett's eyes is one of the best lines in this song: 'Now there's a look in your eyes, like black holes in the sky'.

In the documentary Pink Floyd and Syd Barrett Story, Roger Waters, who wrote lyrics to the song, explains the change in Syd's eyes as he became more unwell, which inspired the lyrics. The documentary shows several portrait pictures of Barrett where one can see the transition. Seeing the documentary made us think of the information we gather by observing our patients. Such information, although not part of the criteria of diagnosing mental illness, provides us with a unique insight to our patients' lives. This kind of evidence is complementary to our formal assessments, but it cannot be measured. The Austrian philosopher Ludwig Wittgenstein, in his monumental work Philosophical Investigations, calls it 'imponderable evidence'. Skilfulness in eliciting such evidence is important for a psychiatrist, something we should not lose in the day-to-day, bureaucratic work. 